Fecha de recepción: abril 2020 Fecha de aceptación: mayo 2020 Versión final: junio 2020

\section{La transformación de los símbolos y significados de los patrones de diseño y los sistemas de producción de indumentaria de la mujer indígena en Guatemala}

Damaris Rebeca Ruyán López ${ }^{(1)}$

\begin{abstract}
Resumen: El presente artículo tiene como objetivo dar a conocer cómo los procesos de globalización, a través de la cultura de masas, transforma los símbolos y significados de los patrones de diseño y los sistemas de producción de indumentaria de la mujer indígena urbana. Para ello se hace una revisión bibliográfica sobre la influencia de la globalización en las culturas prehispánicas y se presenta un análisis gráfico de cómo el diseño y la producción de las prendas de indumentaria se están transformando.
\end{abstract}

Palabras clave: Indumentaria maya - Procesos de globalización - Transformación símbolos - Mujer indígena - Patrones y producción - Diseño y patrones - Diseño y producción.

[Resúmenes en inglés y portugués en la página 175]

(1) Diseñadora Gráfica (Universidad Rafael Landívar). Licenciada en Biblia y Teología. Y candidata a Maestría en Teología del Seminario Teológico Centroamericano. Estudiante de antropología (USAC). Coordinadora del Subprogama de Diseño Gráfico del Insituto de Investigación y Estudios Superiores de Arquitectura y Diseño (URL).

El tema de la indumentaria maya ha sido de interés para ser abordado en Guatemala desde distintas perspectivas a lo largo de las últimas décadas. Actualmente, se observan cambios y transformaciones en los símbolos y significados en los patrones de diseño y los sistemas de producción de la indumentaria de la mujer indígena como influencia de los procesos de globalización a través de la cultura de masas.

El presente artículo tiene como objetivo dar a conocer cómo los procesos de globalización, a través de la cultura de masas, transforma los símbolos y significados de los patrones de diseño y los sistemas de producción de indumentaria de la mujer indígena urbana.

Para ello se hizo una revisión bibliográfica desde la antropología sobre la influencia de la globalización en las culturas prehispánicas, se realizaron visitas a lugares de Guatemala que se destacan por la venta y producción textil indígena como Quetzaltenango, Totonicapán y Salcajá, las cuales fueron de mucha ayuda para comprender tanto la producción artesanal como la producción industrial de la indumentaria de la mujer indígena. A partir 
de algunos ejemplos fotográficos se presenta un análisis de los patrones de diseño y producción tanto de piezas tradicionalmente elaboradas como de vestimenta más contemporánea.

El énfasis en la indumentaria de la mujer indígena se debe a que ésta es una expresión artística propia de la mujer maya, indicador de identidad y diferenciación étnica, vehículo de reivindicación de derechos culturales y políticos (Messina, 2018).

\section{La indumentaria maya en Guatemala}

La indumentaria maya constituye parte integral del desarrollo social y cultural de los pueblos de Guatemala. Las expresiones de la cultura material maya provienen de su herencia prehispánica con el aporte cultural occidental, incorporado desde el siglo dieciséis, que incluyó técnicas, procesos, procedimientos y elementos específicos que dieron como resultado las artes y artesanías populares del pueblo maya contemporáneo (Lara, 2001). Históricamente la cosmovisión maya se refleja en el contenido visual de cada textil. Celso Lara (2001) considera que los textiles son:

( ) una de las expresiones culturales de mayor importancia, tanto utilitaria como ceremonial, social y espiritual, la constituyen los tejidos y textiles mayas, que representan la vida espiritual y de conocimientos milenarios encerrados en sus diseños en los cuales se incrustan figuras de animales míticos, de la cosmogonía y de la naturaleza. Simbolizan asimismo, prestigio y jerarquía social según el tipo de indumentaria, desde los elaborados trajes ceremoniales de lo Aj'Kij, principales y sacerdotes, los de cofrades y mayordomos, hasta los de uso cotidiano (p. 3-4).

La indumentaria de uso cotidiano ha sido elaborada con herramientas y métodos que sobrevivieron a la conquista. En el siglo dieciséis, en la época de la colonia, los españoles introdujeron nuevos métodos y motivos decorativos, incorporaron detalles novedosos con influencias europeas y a raíz de esto los estilos cambiaron. Las mujeres indígenas tejedoras, a pesar de esta situación, preservaron el método tradicional de la producción de indumentaria, el telar de cintura y los patrones de diseño de su indumentaria en los que reflejan la cosmovisión de los pueblos.

A partir del siglo dieciocho, durante la Reforma Liberal, se desarticularon las comunidades, su estructura interna se modificó. Uno de los rasgos visibles que se transformaron fueron los trajes como marcadores de comunidad. La indumentaria se mantuvo principalmente en las mujeres y para los hombres cayó en desuso. Vásquez Monterroso (2017) explica:

[ ] los trajes como marcadores de comunidad. Antes del siglo XVIII los trajes indígenas eran indicadores únicamente de estatus: si eran "principales" eran más elaborados y si eran del común eran más sencillos. Su uso y significación 
se modificó de manera ascendente, es decir, que el común pasó a utilizar los trajes de los principales, aunque ciertos accesorios y estilos siguieron siendo patrimonio de autoridades, elites o especialistas rituales.

Ya en el siglo veinte, se produjeron cambios radicales importantes, producto de la globalización, lo cual desafía a interpretar las realidades sociales y culturales más complejas; es innegable que se puede rastrear los orígenes en la instauración de métodos homogéneos de control de trabajo para diferentes regiones que unificaron estilos locales de producción y consumo (García Canclini, 1996, p. 16). Dentro del marco del capitalismo industrial, el diseño se caracteriza por una doble alianza con la producción en serie y el consumo de masas, y ambos fenómenos han determinado casi todas sus manifestaciones (Sparke, 2010, p. 11). Tanto hoy como ayer, bajo el yugo colonial, las poblaciones se están adaptando o resistiendo a las diferentes manifestaciones de globalización (Genest, 2008).

\section{Actualidad de la indumentaria indígena en Guatemala}

En Guatemala se observan dos procesos socioculturales relacionados con los Pueblos Indígenas: adaptación y resistencia. Ante los procesos globales, la producción de indumentaria maya se ha transformado y se ha incorporado una nueva tecnología de sublimación textil para introducirse al engranaje del mercado internacional.

La sublimación textil es un método que permite estampar cualquier tipo de diseño, desde patrones textiles a moldes de prendas y accesorios. Ésta tiene un amplio campo de aplicación; es un proceso muy versátil ya que una impresora de sublimación trabaja con tecnología inkjet y permite imprimir poca cantidad de metros de tela a costos bajos y con excelente calidad. Aunque, en algunas ocasiones esto no altera la esencia del diseño, sí altera el método tradicional de elaboración de huipiles ${ }^{1}$, su costo y su exclusividad en el diseño.

La mujer indígena se ha visto en la necesidad de modernizarse, los cambios constantes de su indumentaria (los patrones de diseño y los procesos de producción de su indumentaria) reflejan esta tendencia. Una primera aproximación nos muestra un proceso de resistencia en algunos sectores de mujeres indígenas pero de adaptación en las nuevas generaciones de mujeres indígenas, con distintos gustos y necesidades en su manera de vestir, es por ello que se observa la transformación en los símbolos y los significados de la indumentaria a raíz de la cultura de masas.

\section{Aspectos a tomar en cuenta en la elaboración de la indumentaria de la mujer indígena}

A partir del trabajo empírico surgen distintas categorías teóricas para abordar el tema de la transformación que producen los procesos de globalización a elementos considerados tradicionales. Abélè sostiene que las sociedades tradicionales, exóticas, premodernas, ais- 
ladas, comprendidas por la antropología más clásica como totalidades, como colectivos, no existen más. La materia del antropólogo hoy está en un mundo sobremoderno, interconectado, en el que los procesos globales inciden en todas las dinámicas locales, por ende en las identidades culturales (Genest, 2008, p. 282). Así también, la identidad se construye continuamente en un intercambio permanente de ideas que salen de otros contextos; prometiendo algo fijo, duradero, seguro, establecido, un punto de referencia, una constancia, a lo cual cabe preguntarse si frente al frenético ritmo de innovaciones, la idea de identidad estable no se torna en una realidad obsoleta y es sustituida por identidades flexibles (Fernández y Bonsiepe, 2011, p. 11). García Canclini (1989, p. 150) propone que para entender las relaciones indispensables de la modernidad con el pasado se requiere examinar las operaciones de ritualización cultural. Estas operaciones surgen dentro de un proceso de globalización y tradición cultural y abarca todos los ámbitos de la vida. El estudio del antropólogo debe estudiar identidades que se desplazan y se transforman en aspectos tan esenciales como la vestimenta.

La globalización y tradición cultural, los símbolos y significados de la indumentaria de la mujer indígena y su producción tradicional, así como la transformación de los mismos son temas que se abordan a continuación tejiendo el trabajo empírico recopilado con los conceptos analíticos desarrollados a nivel teórico.

\section{Globalización y tradición cultural}

Autores como Immanuel Wallerstein y Aníbal Quijano fijan el momento de la conquista y colonización de América como el inicio de la integración de América Latina al mercado mundial (García Canclini, 1996, p. 16). Esta integración contribuyó a impulsar un desarrollo económico consistente y a la participación en forma competitiva en el intercambio mundial, lo cual ha desembocado en mayores procesos de globalización.

Ante los procesos de globalización, muchos de los que se inquietan por la desaparición de la identidad nacional sitúan la esencia de esa identidad en las tradiciones indígenas y campesinas, o en un folclore nacional que fija en ellas la definición de lo propio (García Canclini, 1996, p. 22). Las identidades se forman y se renuevan cada vez menos en relación con las tradiciones locales, García Canclini diferencia cuatro circuitos de cómo puede afectar la liberalización del comercio el desarrollo cultural:

El histórico-territorial, el conjunto de saberes, hábitos y experiencias organizado a lo largo de varias épocas en relación con territorios étnicos, regionales y nacionales, y que se manifiesta en el patrimonio histórico y la cultura popular tradicional.

El de la cultura de élites, construido por la producción simbólica escrita y visual (literatura, artes plásticas). Este sector abarca las obras representativas de las clases altas y medias con mayor nivel educativo, porque no es conocido ni apropiado por el conjunto de cada sociedad y en los últimos años se ha integrado a los mercados y procedimientos de valoración internacionales.

El de la comunicación masiva, dedicada a los grandes espectáculos de entretenimiento (radio, cine, tv, video). 
El de los sistemas restringidos de información y comunicación destinados a quienes toman decisiones (satélite, fax, teléfonos celulares y computadoras).

La indumentaria de la mujer indígena es un elemento que encaja con el circuito históricoterritorial, ya que encarna un conjunto de saberes que representan la vida espiritual y de conocimientos milenarios y la misma simboliza prestigio y jerarquía social para quien la porta.

Algunas poblaciones indígenas se resisten al cambio y otras se adaptan a las diferentes manifestaciones de la globalización. Esta situación se observa en los distintos puntos de venta de indumentaria tradicional que se visitaron, ya que unas vendedoras se resisten a vender indumentaria industrializada y otras se adaptan a lo que el mercado les demanda ya que persisten las formas de producción masiva. Una vendedora ubicada en el parque de Quetzaltenango manifestó que los huipiles que vendía eran elaborados por las tejedoras con la técnica de telar de cintura y que los huipiles sublimados no la representan. Sin embargo, los vendedores del parque central de la ciudad de Guatemala eligen su producto según la moda del momento, en este caso, las prendas sublimadas con perlas brillantes, colores tipo arcoiris, etc.

\section{La producción tradicional de la indumentaria maya}

Los símbolos y significados y la producción tradicional de la indumentaria maya ha sido el abordaje de las investigaciones del Museo Ixchel del Traje Indígena por más de veinte años. Sus publicaciones tales como Comalapa: el traje y su significado y Zunil: traje y economía, definen cultura como el tejido de significados en términos de los cuales los seres humanos interpretan su experiencia y guían su conducta; por tal razón describen los trajes femenino, masculino e infantil, tanto de diario y ceremonial; enfatizan las categorías y los criterios usados por la comunidad (Asturias y Mejía, 1985 p. 4). Estas investigaciones recopilan los patrones de diseño y enfatizan la producción de los huipiles a través del telar de cintura como forma tradicional.

La vestimenta de la mujer indígena elaborada tradicionalmente está compuesta con los lienzos, los patrones de diseño (colores de hilo y formas), los cuellos y los bordados elaborados a mano. Los lienzos en la mayoría de estos huipiles son dos, con una variante a tres dependiendo del uso y del lugar al que pertenece la prenda (ceremonial o cotidiano). La unión de los lienzos en ocasiones está perfectamente alineada pero en algunas prendas es necesario hacer ajustes.

Los patrones de diseño de los huipiles de Palín, Quiché, San Pedro Sacatepéquez y Quetzaltenango giran en torno a figuras de animales, las figuras geométricas en repetición se observan en huipiles de San Pedro Ayampuc, San Pedro Sacatepéquez (luto y diario) y Santa María de Jesús y las flores en huipiles de Sumpango Sacatepéquez y Todos Santos Cuchumatán. Los cuellos de los huipiles son centrales en la prenda, estos son bordados (Quetzaltenango y San Pedro Sacatepéquez) simples que recubren y protegen e incorporan telas que realzan el cuello de la mujer que lo porta. 
La tejedora elabora los lienzos en telar de cintura y posteriormente se confecciona la prenda, los símbolos y significados de los patrones de diseño están relacionados con la cosmovisión y espiritualidad maya, expresan gráficamente su entorno.

\section{La producción industrial de la indumentaria maya}

Según Esquit (1996, p. 96), las comunidades indígenas están siendo determinadas, por la introducción forzada o la apertura a la tecnología, a las nuevas formas de consumo, otras formas de trabajo, otra manera de observar la ciencia, la organización política y social. La innovación y las nuevas tecnologías han incorporado la sublimación textil y el diseño computarizado de patrones para huipiles, lo cual indica que la vestimenta de uso cotidiano está más sujeta a las modas e innovaciones, las comunidades usan estilos modernos como tradicionales (Jiménez, 2007, p. 100).

Los procesos que transforman los símbolos y significados de los huipiles así como el proceso de producción tradicional de los huipiles de la mujer indígena se relacionan con una nueva tecnología de sublimación textil. Este es un proceso que estampa cualquier tipo de diseño, desde patrones textiles a moldes de prendas y accesorios. Existe además, la producción computarizada de patrones de diseño en los huipiles.

Tanto en la ciudad de Guatemala como en puntos de distribución de Salcajá, se observaron distintas prendas que incorporan elementos de tipo industrial desde brillantes hasta la sustitución de los hilos por tintas. En Cantel, Salcajá, Quetzaltenango y Ciudad de Guatemala los vendedores expresaron la influencia de la moda ya que a las mujeres indígenas les gustan las impresiones con incrustaciones de pedrería. En Salcajá se encuentran los impresores y en el local H\&G Sublimaciones, ofrecen sublimaciones de cortes en alta definición con diseños originales y precios accesibles. Un huipil sublimado ya no posee un diseño elaborado por la tejedora de algún lugar o región sino ahora los patrones son diseñados por los dueños de las sublimadoras.

El impacto de la globalización en relación a los sistemas de producción es visible en la calidad del producto. Los procesos de sublimado son mucho más rápidos, las prendas poseen un acabado detallado o no, todo depende del precio que la persona quiera pagar. Los productores se han incrementado y diversificado en los municipios productores y distribuidores de indumentaria indígena.

La globalización juega un papel central en la transformación de los símbolos y significados de los patrones de diseño de las prendas de indumentaria maya. Al estudiar los movimientos recientes de globalización se advierte que estos procesos segregan, producen nuevas desigualdades y estimulan reacciones diferencialistas (García Canclini, 2001, p. 24). La globalización empresarial y del consumo se aprovecha para afirmar y expandir particularidades étnicas o regiones culturales.

Las comunidades indígenas enfrentan la sociedad moderna y la globalización desde múltiples espacios. Las mujeres indígenas enfrentan de muchas formas el proceso de modernización que se produce en Guatemala y el mundo (Esquit, 1996). La identidad tradicional está cambiando en muchos sentidos y para la eliminación de la precariedad en las 